\title{
CIHR audits suggest concerns with reform leadership
}

A $s$ the Canadian Institutes of Health Research (CIHR) prepared for a July 13 meeting with 47 scientists opposed to sweeping reforms to its granting procedures, questions were arising about the institute's leadership. Six senior scientists contacted by CMAJ said two 2016 audits of the CIHR's reforms and its response to them compel concerns about high-level decisions.

"It may be time to renew the leadership,"said Dr. Quim Madrenas, Canada Research Chair in Human Immunology at McGill University.

The two audits, one external and one internal, "certainly identify positive aspects of CIHR, in a way that is not surprising," said Madrenas. However, CIHR's response to the audits "does not address the fundamental problem of the lack of effective CIHR leadership in nurturing and promoting a positively engaged research community, and securing a high profile and funding for Canadian health research," said Madrenas.

He notes that the Internal Audit Consulting Engagement Report, dated February 2016, reveals that decisions have been taken "without the full information that would assist in appropriate planning."

Reforms CRM Project Independent Third Party Review, conducted by Ottawa-based Interis Consulting, also raises concerns about CIHR's management of its reforms. Citing "a lack of consistency, integration and especially communication and information on all aspects of project management." The external audit, dated January 2016, warns that the "scope and requirements management are not integrated, clear or apparent including and especially an end-state vision/strategic road-map."

Of special concern, said Madrenas, is the adoption of a "virtual" approach to peer review that eliminated face-toface meetings within an ambitious suite of reforms implemented at the
CIHR. "Upon implementation of the reforms, it has become clear that we now have a serious problem with peer review," said Madrenas.

Jim Woodgett, director of research at the Lunenfeld-Tanenbaum Research Institute in Toronto, agrees the audits raise questions about the leadership behind the reforms. Managers there, he charges, "basically designed an idealized rainbow unicorn plan and rolled it out without consideration for the real world."

CIHR, which is entrusted with about $\$ 1$ billion annually by the federal government, declined a $C M A J$ interview request about the audits and management's response to them. CIHR also declined to answer written questions pending the July 13 meeting.

In an online statement, CIHR notes that the audit conducted by staff "found that the reform implementation project benefited from well-developed planning tools" and that the pilots kept to their timelines. CIHR also stated the

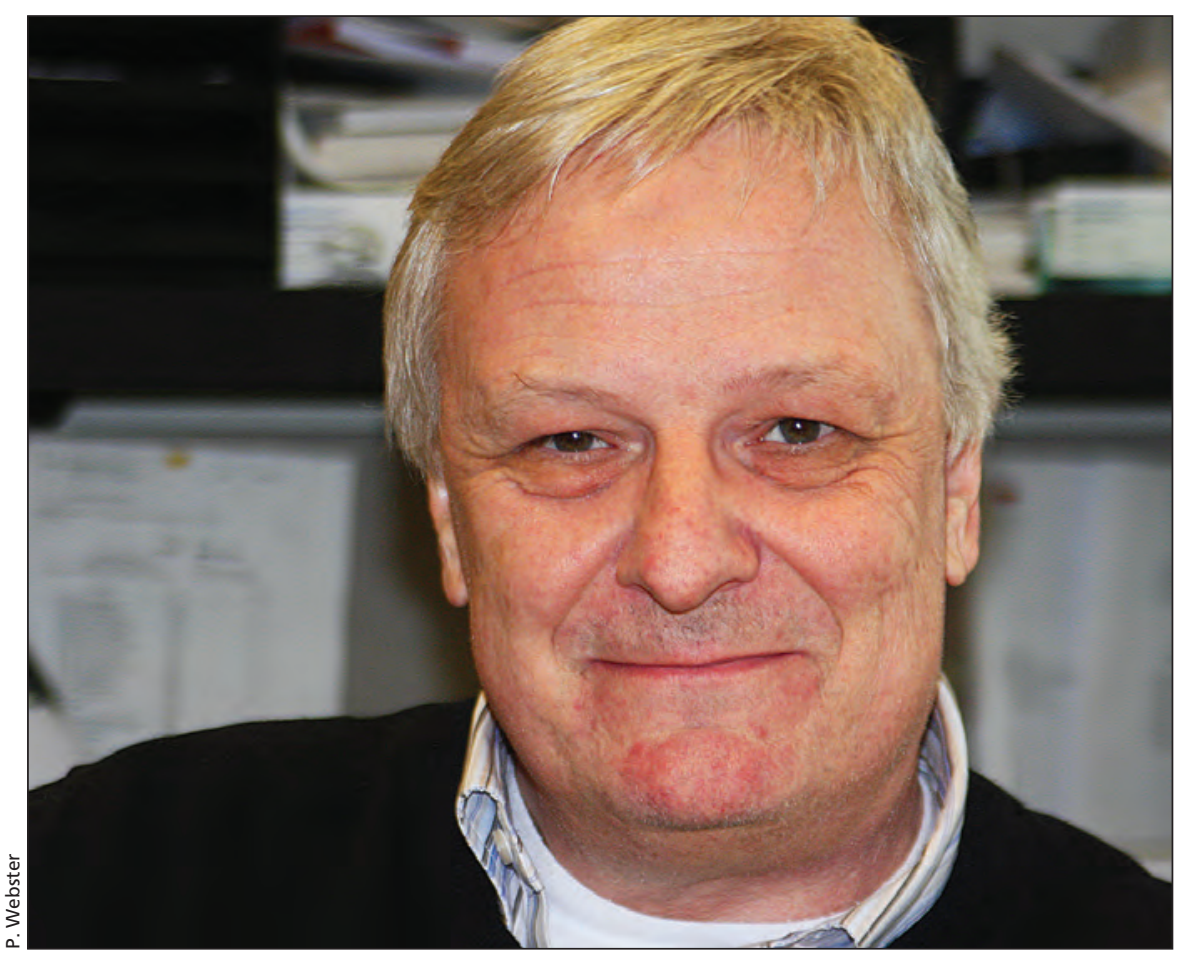

CIHR rolled out reforms "without consideration for the real world," said Jim Woodgett, director of research at the Lunenfeld-Tanenbaum Research Institute. audit "found opportunities for improvement in the areas of information-sharing, communications, reporting, project planning, and stakeholder engagement, all of which are being addressed by CIHR."

But what CIHR did not include in its published statement is that its internal auditors found that "significant improvements are necessary to strengthen governance, risk management and control practices."

CIHR acknowledged that an external audit recommended "clarifying roles and responsibilities as well as project schedules and scope" and stated that "CIHR is currently taking steps to implement the report's recommendations such as establishing new governance committees to monitor scope and timelines for the projects." However, CIHR did not publicly acknowledge that the audit concluded that it was not "on track" on any of the auditors' seven "topics of enquiry,", and that it faced "significant risks" in each. 
CIHR responded to the audits in a May 2016 document stating that in the future it will conduct "more fulsome analysis of operational resource and cost impacts, prior to proceeding with any change." In addition, a steering committee "has been reconstituted, will meet bi-weekly, and have full oversight of the administrative, financial management, and project planning functions for the reforms."
CIHR reforms. "Even internally, they don't know why they are doing this," he said. "It's become a cynical exercise of executing management decisions."

Lisa Porter, scientific director of the Windsor Cancer Research Group at the University of Windsor, said that the audits expose confusion within CIHR over whether its reforms were actually ever needed. "None of us are clear why these changes were ever

\section{"As a scientific community we have been vilifying the CIHR as a whole but I think that should be directed at the people at the top."}

Madrenas and Woodgett's views on CIHR's leadership are shared by other senior researchers. Ravi Menon, Canada Research Chair in Functional and Molecular Imaging at the Robarts Research Institute, University of Western Ontario said the audits are both alarming and revealing. "As a scientific community we have been vilifying the CIHR as a whole but I think that should be directed at the people at the top. I think many people within the CIHR's institutes, which are themselves being reformatted and decimated, are very concerned about the leadership," he said.

Michael Rudnicki, senior scientist and director of the Regenerative Medicine Program at the University of Ottawa, describes the audits as "shockingly damning" for the leadership of the made," Porter said. She cited an international review of the CIHR that endorsed its original design shortly before it was radically changed. "How much more money and reviews will this take to accomplish something that was never necessary?"

Phillip Hieter, a principal investigator at the Michael Smith Laboratories at the University of British Colombia in Vancouver, said the audits confirm that "many of the things attempted in the CIHR reforms were highly risky." He noted that although the "CIHR's reforms to the peer-review process were perhaps the riskiest," the audits do not address this aspect of the reforms.

At the request of federal Health Minister Dr. Jane Philpott, CIHR executives met July 13 with 47 scientists who repre- sented more than 1250 researchers who signed a letter asking CIHR to reverse changes to its grants process, including the decision to replace face-to-face peerreview meetings with an online system.

The meeting was purportedly to "jointly address concerns" about the new review process, with the aim of developing "practical and pragmatic solutions for improving peer review," according to a CIHR statement. The peer-review reforms are part of changes at CIHR that attracted critical scrutiny from the presidents of 15 universities in a Jan. 29 letter to CIHR President Dr. Alain Beaudet citing "serious concerns and many unanswered questions."

Beaudet released a statement defending the reforms as an effort to "to improve the sustainability of our health research system, the transparency and fairness of our granting processes, and the quality and impact of the research supported by federal investments." However, he acknowledged that the online system "has raised serious concerns among applicants and reviewers alike. These concerns must be addressed since CIHR can only be successful it if has the support and confidence of the research community. This working meeting represents an important next step toward re-establishing that support and confidence." - Paul Webster, Toronto, Ont.

With files from Barbara Sibbald, CMAJ

CMAJ 2016. DOI:10.1503/cmaj.109-5301 